\title{
Novel Technological Developments with Impacts on Perspectives for Mobile Nuclear Power Plants
}

\author{
Luciano Ondir Freire, Delvonei Alves de Andrade \\ Nuclear Engineering Center, Instituto de Pesquisas Energéticas e Nucleares (IPEN-CNEN/SP), São Paulo, Brazil \\ Email: luciano.ondir@gmail.com
}

How to cite this paper: Freire, L.O. and de Andrade, D.A. (2021) Novel Technological Developments with Impacts on Perspectives for Mobile Nuclear Power Plants. World Journal of Nuclear Science and Technology, 11, 141-158.

https://doi.org/10.4236/wjnst.2021.114011

Received: June 29, 2021

Accepted: September 5, 2021

Published: September 8, 2021

Copyright $\odot 2021$ by author(s) and Scientific Research Publishing Inc. This work is licensed under the Creative Commons Attribution International License (CC BY 4.0).

http://creativecommons.org/licenses/by/4.0/

\begin{abstract}
New research developments suggest that nuclear reactors using fusion may enter the market sooner than imagined even for mobile applications, like merchant ship propulsion and remote power generation. This article aims at pointing such developments and how they could affect nuclear fusion. The method is enumerating the main nuclear reactors concepts, identifying new technological or theoretical developments useful to nuclear field, and analysing how new recombination could affect feasibility of nuclear fusion. New technologies or experimental results do not always work the way people imagine, being better or worse for intended effects or even bringing completely unforeseen effects. Results point the following designs could be successful, in descending order of potential: aneutronic nuclear reactions using lattice confinement, aneutronic nuclear reactions using inertial along magnetic confinement, hybrid fission-lattice confinement fusion, and fission reactions.
\end{abstract}

\section{Keywords}

Fusion Reactors, Mobile Nuclear Power Plants, Nuclear Reactors, Nuclear Merchant Ships, Clean Energy

\section{Introduction}

Most commerce is done by the seas and ships contribute significantly to greenhouse gases emission and most of costs come from the fuel, which may increase with new regulations. From an energy security point of view, the fact that petrol is concentrated in few politically unstable countries is a large incentive to search for new forms of energy. 
Furthermore, economic development requires growing and stable energy matrix and any interruption in energy supply may be catastrophic as even food production, transport and conservation depend on energy.

Today, some enterprises claim they may deliver mobile nuclear reactor within 10 to 20 years from now, providing cheap and clean energy. Recent breakthroughs on superconducting materials and magnetic fields give hints that those claims may even be truer than those enterprises imagined. On top of that, new discoveries suggest that current nuclear models need revision and that new types of nuclear reactors could be feasible.

Nuclear reactors are currently divided into generations:

- First generation was prototypes.

- Second generation was the first commercial solutions.

- Third generation is the advanced PWR designs.

- Fourth generation is concepts of future reactors that would be highly economical and proliferation resistant, and they would generate minimal waste and have enhanced safety.

This work focuses on yet another generation of nuclear reactors, based on nuclear reactions of light elements, instead of the previous ones that use fission of heavy elements, like Uranium and Plutonium. A fifth generation would be nuclear reactors using light elements and would produce no radioactive waste, have little need for radiological protection, and be one order of magnitude more economical than fossil fuels.

In past, there were four nuclear merchant ships [1]:

- NS Savannah (1962), US, second generation, early retired in 1971 due to economic reasons.

- NS Otto Hahn (1969), Germany, second generation, converted to diesel due to difficulties to access ports, as local authorities did not accept a nuclear ship due to fear of radioactivity.

- NS Mutsu (1972), Japan, second generation, plagued by design errors resulting in radiation leak and local society blockades due to fear of radioactivity.

- NS Sevmorput (1988), Russia, third generation, also had difficulties accessing ports, as local authorities did not accept a nuclear ship due to fear of radioactivity after Chernobyl accident.

In the last years, both Russia and China have been investing in nuclear barges meant to provide cheap energy in remote places, accelerating the development in those areas. Russia already has the nuclear barge named Akademik Lomonosov in operation since 2019, which has a thermal power of $300 \mathrm{MWt}$ and produces up to $70 \mathrm{MWe}$ of electricity. The other five nuclear barges were ordered by Russian government in 2021 [2]. China is building the first floating nuclear power plant called ACPR50S with a thermal power of $200 \mathrm{MWt}$ and electrical power of $60 \mathrm{MWe}$, starting in 2016 and China is planning to finish it in 2022. Russia also has maintained fleet of nuclear icebreakers for local shipping for some decades.

Other than locally operated ships and nuclear barges, nuclear fission-powered 
ships face regulation issues due the long-lived radioactivity, so the use of fission for merchant shipping is risky for the investor because there is not agreed safety standard for all countries.

There are not global agreements on the nuclear safety requirements, meaning that every country may make its own regulations, regulations may become distinct and even conflicting and worse, countries may change regulations at will.

The lack of uniformity in safety requirements is an externality and source of risk that kills any private investor incentive to develop a nuclear design for merchant shipping.

Another issue is the responsibility over the spent fuel as private companies may become bankrupt and leave a large problem of unmanaged spent fuel, so only governments have made investments in nuclear merchant ships and nuclear barges. Further, their use is meant to be limited to a single country and its close partners who subscribe to the same nuclear rules.

The reason for those difficulties is the intrinsic nature of fission of large nuclei, that leaves a large array of fission products that are radioactive for a long time. The management of risks associated to such products require large investments and people tend to associate nuclear power with nuclear weapons and their terrifying effects, which in turn leads to rules much stricter for nuclear power than for other types of power. Historical records show that nuclear power is one of the safest power sources, much safer than hydro or coal [3], but people in western countries have more fear of nuclear power. It is a fact that people forget easily accidents claiming hundreds of human lives in renewables, like dam ruptures, but do not forget nuclear accidents without direct deaths, like Fukushima and Three Miles Island.

Nuclear reactions using light elements would have no long-lived radioactivity, even if radiation is indeed produced during operation, after shutdown, there is not radiation nor radioactivity, meaning it is a clean energy. Of course, assuming people will decide according to reason, no country would impose safety requirements for fusion reactors distinct than those for X-ray generators.

Academically, many proposals of designs of Small Modular Reactors (SMR) using fission reactions appeared in recent years, but none solves the regulatory and spent fuel issues, although safety and economics are greatly improved over the second-generation reactors. Therefore, this work will concentrate in fusion reactors designs that could power a ship and are part of a new generation of nuclear reactors, a fifth generation.

It is important to recall some definitions to the reader, being the first the concept of fission and fusion. Fission is the phenomenon where a larger atom is divided in smaller atoms while fusion is the junction of two atoms into a larger one. The fissions of Uranium and Plutonium are the most famous, but light elements also suffer fission, like Boron in the ${ }^{11} \mathrm{~B}(\mathrm{p}, 2 \text { alpha })^{4} \mathrm{He}$ or Lithium in the ${ }^{7} \mathrm{Li}(\mathrm{p} \text {, alpha })^{4} \mathrm{He}$ reactions. However, for those last two examples, people tend to use the word "fusion" because they are technologically more akin to fusion reac- 
tions than fission reactions, in the sense they are clean and leave no radioactivity.

Other important concepts are those of neutronic and aneutronic reactions, as neutrons are the best way to heat atoms and cause fission but have a large array of undesirable effects. Energetic neutrons are ionizing radiation, and they have a high penetration power, requiring large radiological shielding, besides causing radiation damage to materials. Many nuclides capture neutrons, becoming radioactive elements (neutron activation) and other nuclides generate intense gamma radiation under neutron radiation due inelastic scattering. Neutron damage imposes frequent material replacement, neutron activation generates radioactive waste, shielding add volume and weight. Material replacement, radioactive waste, volume, and weight together contribute to increase life cycle costs of a nuclear power plant, particularly if it is mobile.

On the other hand, aneutronic nuclear reactions, like ${ }^{11} \mathrm{~B}(\mathrm{p}, 2 \text { alpha })^{4} \mathrm{He}$ or Lithium in the ${ }^{7} \mathrm{Li}(\mathrm{p} \text {, alpha })^{4} \mathrm{He}$, are clean, do not require large shielding and do not generate material damage. The drawback is they require larger energies to overcome Coulomb barrier, so people directed the larger portion of investment in research on fusion reactors to neutronic reactions.

Another fundamental concept is the Technological Readiness Levels (TRL), that are objective stages of maturity of a technology for use and constitute a powerful risk mitigation technique for systems engineering. This work adopted the NASA technological readiness levels, presented at Figure 1.

In fusion reactors, the concept of "Coefficient of Performance" (COP) is the ratio of energy output over energy input. Assuming the input is electrical energy and a global thermal cycle of $40 \%$, a reactor with COP $=2.5$ barely sustains itself, so this level is absolute minimum to consider in mobile nuclear power plants. In practice, COP should be beyond 5 ( $50 \%$ of generated power is used by reactor) to allow commercial applications, meaning that for mobile NPP, to go beyond TRL3, COP must be larger than 5 .

This work evaluates TRL only for the black box receiving electric power and generating heat, and not for the global system generating electricity, as integration problems add further development but should not present large risks.

Another assumption is that the technical difficulty to develop a technology is proportional to the required financial investment alone, ignoring time or personnel qualification.

Nuclear reactors are divided in generations, where the first generation were prototypes, the second were the first commercial solutions, the third are the advanced PWR designs and fourth are concepts of future reactors. The fourth generation would be highly economical and proliferation resistant, it would have minimal waste and enhanced safety. Amongst the fourth-generation concepts are the molten salt reactors. This work focuses on another generation, yet beyond fourth generation, having truly little or no radioactive waste, little need for radiological protection, being much more economical than fossil fuels. That 


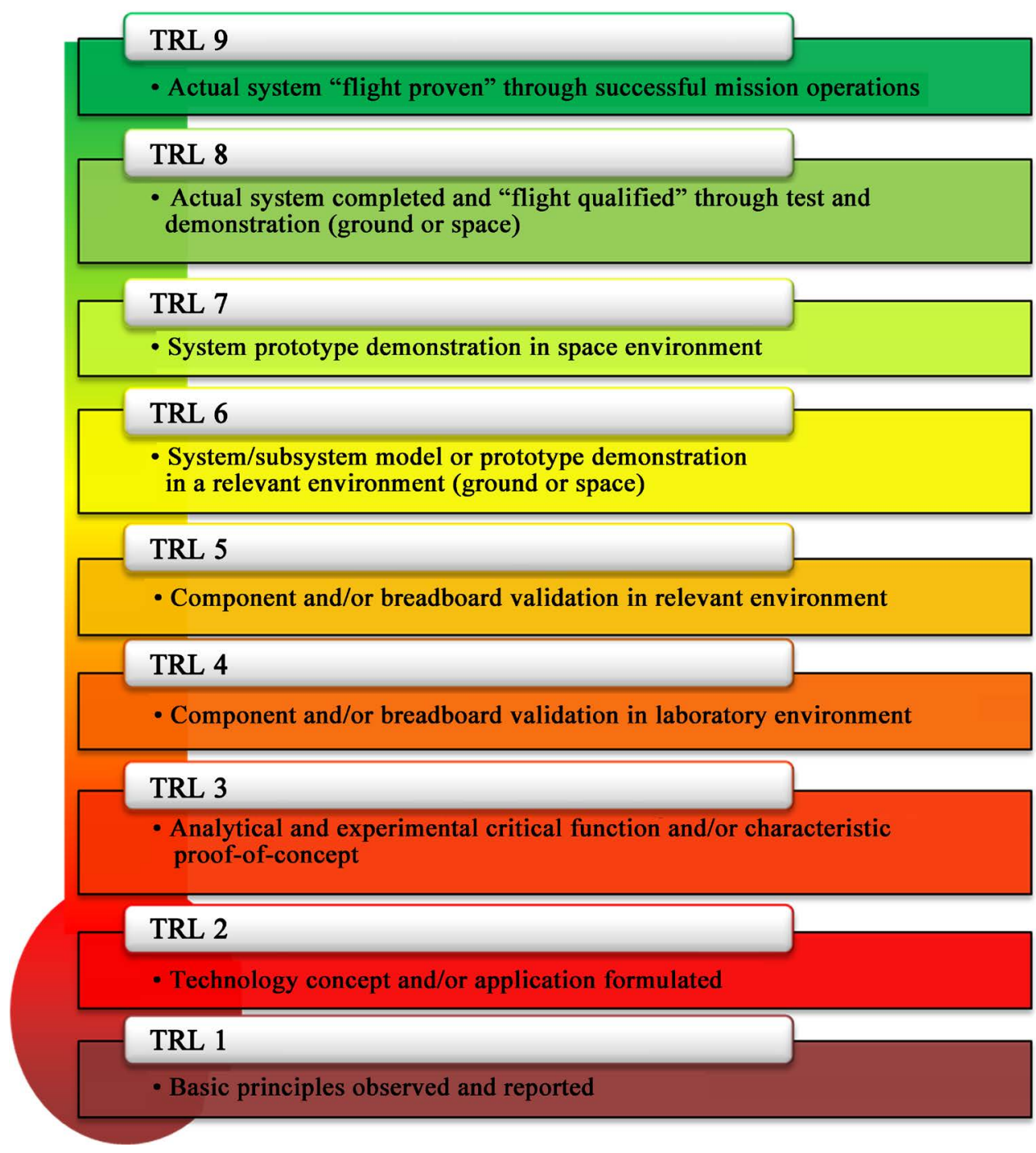

Figure 1. NASA Technology Readiness Level (TRL).

would be the fifth generation, based on nuclear reactions of light elements and emerging technologies, representing a true game changer in energy market and in greenhouse gases emissions.

The motivation is to present the reader the status of research and private investments (nuclear technology start-ups) on various types of nuclear reactors using light elements, identifying how this field could be impacted by new developments in science and technology. Fission reactors using heavy elements are not studied because their radioactive waste (although manageable, as Navies demonstrate and with smaller risk than other power sources [3]) scares people and until education advances world-wide, democratic countries are not likely to accept radioactivity risks.

This work concentrates in mobile applications because they are also applicable to larger land-based or static power plants, but technologies applicable to land-based energy production are not necessarily applicable for mobile applications. Currently, given the global supply chains, transportation is so vital as energy production, so 
research on mobile applications (merchant ship propulsion, remote power plants, aircraft propulsion, space propulsion) has a broader impact. Them main contribution is to make the reader aware of the developments related to the nuclear field that could affect the propulsion of merchant ships.

\section{Method}

The first step is to identify the main nuclear reactors families along their technological readiness for mobile applications.

The second step is to identify recent discoveries of physical laws and new technologies that could impact the status of nuclear reactors.

The third step is to combine those developments with each family to wonder which new concept could emerge.

The fourth step is to analyse the risks and potential gains associated with each concept, identifying interesting avenues for research.

The fifth step is to present some promising start-ups and their technical propositions, making the reader more familiar with the fusion field.

\section{Development}

Pressurized Water Reactors are sea-proven, used for several merchant ships and many military ships, particularly for submarines. However, the quantity of high-quality pressure vessels has made them too expensive because of capital costs, while fuel is inexpensive. As nuclear reactors experience scale economy, larger reactors have better changes of becoming competitive, and authors estimate that the minimal nominal power (to compete with diesel propulsion) would be about $50 \mathrm{MW}$ electrical (around 200 - $240 \mathrm{MW}$ thermal). This value explains the rated power of both Russian and Chinese floating nuclear power plants, that should be as smaller as possible to increase the number of potential clients, but large enough to allow scale economy to become competitive with fossil fuels.

Molten-Salt Reactors (MSR) eliminates the need of pressure vessels, but because of lack of political support, the US Oak Ridge National Laboratory stopped the development of this technology. The MSR experiment run without problems from 1965 to 1969 and was an evolution of Aircraft Reactor Experiment (ARE), being compact and light [4]. As it worked around $650^{\circ} \mathrm{C}$, it allowed high efficiency thermal cycles, but this concept stopped at laboratory demonstrations stage. If research is done, authors estimate that $17 \mathrm{MW}$ electrical MSR could be competitive with diesel propulsion.

Liquid Metal Reactors (LMR) already powered military submarines both in URSS and US, but had safety issues and PWR became the standard, although LMR had better power density than PWR.

This work considered RMBK, CANDU and HTGR to have low power density (too large) for ship propulsion, where volume and weight are critical. Boiling Water Reactors (BWR) could be even more compact than PWR, but heave mo- 
tions or shocks could have impact in reactivity by changing the moderator density within the reactor, meaning that BWR cannot be an option.

For ships, even with recent advances in superconductors, magnetic confinement fusion reactors (TOMAKAK, stellarators) probably would not fit in a ship because they need large coils, cooling for those coils, shielding for the neutrons and their shape is not the most adequate for arrangement in a ship. Therefore, the hybrid fission-fusion concepts, which use a fissionable blanket to generate heat and a fusion reactor to provide neutrons, also do not fit in ships.

Inertial confinement fusion reactors typically use lasers to compress light atoms to the point to obtain fusion reactions in a small sphere of fuel (deuterium, tritium), generating heat and neutrons. Although compact, this approach has trouble with low efficiency of lasers and with the radiation damage issues. Therefore, for the medium term, ships probably will not have nuclear reactors based on inertial confinement fusion nor in hybrid concepts using fission.

Some enterprises start to make claims of researching compact fusion reactors designs that could be so compact that they would fit in a truck load and could power airplanes. Such designs rely in a mix of magnetic and inertial confinement and use formats more adequate to embark in a ship. Examples of innovative enterprises are Lockheed Martin Compact Fusion Reactor, General Fusion, TAE Technologies (former Tri-Alpha Energy), Lawrenceville Plasma Physics (LPP), HB11 and Zap Energy. Some of those use aneutronic reactions, the proton plus Boron-11 fission reaction that produces 3 alpha particles, reducing the need of shield, costs, volume, and weight. Further, some designs use direct energy conversion, which uses the energy from plasma to generate electricity, or photoelectric effects to generate electricity from X-rays. However promising, those technologies did not demonstrate yet a COP larger than 1 .

Lattice Confinement uses loading of Hydrogen isotopes in conductors' lattice by diverse methods (electrolysis, glow discharge, gas loading, ion beams) and heating the lattice with radiation, thermal energy, lasers or accelerated ions. Another group of enterprises develop energy products based on Lattice Confinement reactors, like E-Cat, Industrial Heat and Brillouin Energy.

The nuclear reactors families are listed in Table 1.

After reviewing the current promising technologies, Table 2 presents recent discoveries in the nuclear reactions field.

After listing the theoretical and technological advances, it is important to identify the potential impacts in technologies. PWR could use deuterated metal rods to help in moderation and produce extra neutrons, allowing the use of natural Uranium, Thorium and spent fuel from PWR. It could be a cheap refit, but the potential gains are small, as the fuel cost is small (about $5 \%$ of energy price), even with enrichment, and fuel rod life depends also on radiation damage, not only on reactivity. As enrichment is about one third of fuel cost, costs improvements would be in $1 \%-2 \%$ range.

For LMR, aneutronic reactions in a deuteride/hydride metallic fuel could help 
Table 1. Families of nuclear reactors and their technological readiness.

\begin{tabular}{|c|c|c|}
\hline Family & Subfamily & Readiness Level \\
\hline \multirow{7}{*}{ Fission } & PWR & 9 \\
\hline & MSR & 4 \\
\hline & RMBK & Theoretically unfeasible \\
\hline & CANDU & Theoretically unfeasible \\
\hline & HTGR & Theoretically unfeasible \\
\hline & BWR & Theoretically unfeasible \\
\hline & LMR & 8 \\
\hline \multirow{3}{*}{ Hybrid Fission-Fusion } & Molten salt-Magnetic Confinement & Theoretically unfeasible \\
\hline & Molten salt-Inertial Confinement & Theoretically unfeasible \\
\hline & Magnetic Confinement & Theoretically unfeasible \\
\hline \multirow{3}{*}{ Fusion* } & Inertial Confinement & Theoretically unfeasible \\
\hline & Magnetic and Inertial Confinement & 3 \\
\hline & Lattice Confinement & 7 \\
\hline
\end{tabular}

${ }^{\star}$ Technically, some of the technologies use fission reactions, like ${ }^{11} \mathrm{~B}(\mathrm{p}, 3 \mathrm{alpha})$ reactions, but people call indistinctively "fusion" when using light elements.

Table 2. Recent discoveries.

Name
Cross section enhancements
in conductors
$\begin{aligned} & \text { Neutron multiplication in } \\ & \text { deuterated Pd }\end{aligned}$

\section{Description}

The probability of fusion reactions in conductors' lattice is higher than in gas or plasma. This effect is often called "Screening", meaning that the Coulomb barrier is lowered in a conductive solid [5] [6] [7]

Researchers found that saturating Palladium metal with Deuterium and submitting it to neutron beam results in a neutron multiplication, suggesting neutrons can start nuclear chain reactions in deuterated Palladium [8] [9]

Nuclear Transmutations in Solids

Some conductors, typically Palladium, Nickel, Gold, graphite, upon Hydrogen isotopes loading (for instance, by electrolysis, gas loading, glow discharge), present a large array of new elements, both lighter and heavier, suggesting fission and fusion reactions [10], along large liberation of heat

New superconductors at higher temperatures

High-temperature superconductors (like Bismuth strontium calcium copper oxide, Yttrium barium copper oxide) have superconducting properties at temperatures above liquid nitrogen boiling point $\left(77^{\circ} \mathrm{K}\right)$, easing the cooling of magnets

Neutron generation in deuterated metals

Deuterated metals, like Titanium, Palladium, Erbium, present neutron emissions under neutron, electron beam or gamma radiation. If subjected to a radiation beam, the quantity of neutrons (and nuclear reactions along a large number of new elements) increases greatly [9] [11] [12] [13]

Plasmoids

Plasmoids are plasma magnetically confined within a magnetic bottle generated by currents that flow in the plasma itself, rather than in external coils. In other words, plasmoids use magnetic self-compression to achieve plasma pressures required to fusion. Plasmoids have limited lifetime (micro or milliseconds scale), being unstable, but may have a role in pulsed regimes [14] 
to remove part of radioactive waste, improve moderation (better reactivity due presence of Hydrogen or Deuterium). Screened fusion reactions of Deuterium with Deuterium (either in a metallic fuel or in molten coolant) could also provide reactivity boost allowing the use of natural Uranium, Thorium, or even radioactive waste. However, the transmutation in coolant may generate corrosion and neutron-absorbing isotopes, meaning that this potential use is not certain. Further, those potential advantages do not correct the fundamental problems of LMR, like corrosion, plugging, and high exothermal chemical reactions with water (for Sodium cooled reactors).

For designs using magnetic confinement (including fusion-fission hybrids and inertial-magnetic hybrids), the advent of high temperature superconductors allows the generation of higher intensity fields. Such fields allow confinement of particles at higher temperatures, improving fusion rates or reducing magnets size, which is critical for mobile applications.

MSR could have a large improvement in fuel flexibility by adding deuterated metals to moderate neutrons and generate extra neutrons, boosting reactivity and allowing the use of natural Uranium, Thorium, and radioactive waste as fuel. As MSR does not have heavy and high-quality pressure vessels, its capital cost should be smaller than PWR, meaning that fuel cost would be more relevant, in $10 \%-15 \%$ range, meaning that up to $5 \%$ reduction in energy costs could be achieved. However, there is risk that the generation of new elements in the deuterated metal lattice would absorb neutrons and prevent long term operation.

For combined inertial and magnetic confinement designs, the use of a deuterated or tritiated metal pellet could enhance the reaction yield by various orders of magnitude, as Hydrogen isotopes in metals are about 7 to 9 orders of magnitude denser than in current magnetic confinement plasmas. Besides, there is also the screening effect that enhances the reaction yield by reducing the Coulomb barrier along with the higher mass of metal atoms acting as a cage for small time periods. Similar arrangement is used in nuclear weapons, that may use deuterated Lithium and an external shell of Uranium.

Lattice confinement reactors (using Nickel-Hydrogen and $\mathrm{LiAl}_{4}$ additive) theoretically use the cross-section enhancement in conductors to allow proton capture by metal atoms nucleus. Current nuclear models do not predict such phenomena, which, if proven true, should require a revision of nuclear forces theory, which would not be the first theoretical shift in history.

The cross-section enhancement in conductors apparently enables the occurrence of chain reactions of aneutronic nuclear reactions in specific combinations of atoms, like Boron-Hydrogen [15], Palladium-Deuterium [7], Lithium-Hydrogen [16], Tungsten-Hydrogen [17], Carbon-Hydrogen [18]. Such chain reactions lead to the appearance of hot spots with new elements in the solid lattice, along with heat, X-rays, charged particles and, in some cases, a few neutrons. Those reactions tend to increase with application of energy on the solid and enables the development of solutions like E-Cat or Brillouin Energy's CECR. Such type of 
reactor generates $\mathrm{X}$-rays that easily shielded and do not produce radioactive products, meaning they should provide a very inexpensive power source.

Table 3 presents the summary of potential impacts of all mentioned discoveries on the aforementioned types of reactors along with the risks.

\section{Results}

It is important to summarize the effective gains in energy costs, as estimated by the authors and Table 4 presents both foreseen upsides and downsides of investing at each subfamily of reactors.

\section{Discussion}

It is important to discuss the current fusion enterprises and the first is TAE fusion power, former Tri-Alpha Energy, which is a mention of the result from proton and Boron fusion (three alpha particles). It is a US company that uses

Table 3. Potential impacts.

\begin{tabular}{|c|c|c|c|c|c|}
\hline Subfamily & $\begin{array}{l}\text { Cross section } \\
\text { enhancements in } \\
\text { conductors }\end{array}$ & $\begin{array}{l}\text { Neutron } \\
\text { multiplication in } \\
\text { deuterated } \mathrm{Pd} / \\
\text { Neutron generation } \\
\text { in deuterated metals }\end{array}$ & $\begin{array}{l}\text { Nuclear } \\
\text { Transmutations } \\
\text { in Solids }\end{array}$ & $\begin{array}{l}\text { New } \\
\text { superconductors } \\
\text { at higher } \\
\text { temperatures }\end{array}$ & Plasmoids \\
\hline PWR & Not applicable & $\begin{array}{l}\text { Deuterated metals } \\
\text { could boost reactivity }\end{array}$ & $\begin{array}{l}\text { New elements } \\
\text { may generate } \\
\text { poison }\end{array}$ & Not applicable & $\begin{array}{l}\text { Pulsed neutron sources } \\
\text { could boost reactivity in } \\
\text { subcritical reactors }\end{array}$ \\
\hline MSR & $\begin{array}{l}\text { Deuterated metals } \\
\text { could boost } \\
\text { reactivity }\end{array}$ & $\begin{array}{l}\text { Deuterated metals } \\
\text { could boost reactivity }\end{array}$ & $\begin{array}{l}\text { New elements } \\
\text { may generate } \\
\text { poison }\end{array}$ & Not applicable & $\begin{array}{l}\text { Pulsed neutron sources } \\
\text { could boost reactivity in } \\
\text { subcritical reactors }\end{array}$ \\
\hline LMR & $\begin{array}{l}\text { Aneutronic } \\
\text { reactions could } \\
\text { enhance power } \\
\text { density, burn waste, } \\
\text { Hydrogen isotopes } \\
\text { would help } \\
\text { moderation }\end{array}$ & $\begin{array}{l}\text { Deuterium in coolant } \\
\text { could boost reactivity } \\
\text { and moderate }\end{array}$ & $\begin{array}{l}\text { New elements } \\
\text { may generate } \\
\text { poison }\end{array}$ & Not applicable & $\begin{array}{l}\text { Pulsed neutron sources } \\
\text { could boost reactivity in } \\
\text { subcritical reactors }\end{array}$ \\
\hline $\begin{array}{l}\text { Molten } \\
\text { salt-Magnetic } \\
\text { Confinement }\end{array}$ & Not applicable & Not applicable & Not applicable & $\begin{array}{l}\text { Increase } \\
\text { temperatures and } \\
\text { fusion rates }\end{array}$ & Not applicable \\
\hline $\begin{array}{l}\text { Magnetic and } \\
\text { Inertial } \\
\text { Confinement }\end{array}$ & $\begin{array}{l}\text { Use of } \\
\text { deuterides/hydrides } \\
\text { metals targets may } \\
\text { enhance reaction } \\
\text { rates }\end{array}$ & $\begin{array}{l}\text { Impose shielding for } \\
\text { use of deuterated } \\
\text { metals }\end{array}$ & No relevant effect & $\begin{array}{l}\text { Increase } \\
\text { temperatures and } \\
\text { fusion rates }\end{array}$ & $\begin{array}{l}\text { Plasmoids could allow } \\
\text { fusion with simple and } \\
\text { cheap apparatus }\end{array}$ \\
\hline $\begin{array}{l}\text { Lattice } \\
\text { Confinement }\end{array}$ & $\begin{array}{l}\text { Allows chain } \\
\text { aneutronic reactions }\end{array}$ & $\begin{array}{l}\text { Impose shielding for } \\
\text { use of deuterated } \\
\text { metals }\end{array}$ & $\begin{array}{l}\text { Limits the } \\
\text { burn-up }\end{array}$ & Not applicable & $\begin{array}{l}\text { Pulsed neutron sources } \\
\text { could stimulate nuclear } \\
\text { reactions in lattice }\end{array}$ \\
\hline
\end{tabular}


Table 4. Risk and potential gains table.

\begin{tabular}{|c|c|c|c|}
\hline Sub-family & Status & Potential gain (upside) & Risks (downside) \\
\hline PWR & $\begin{array}{l}\text { Proven, but seen as too } \\
\text { risky. Economic feasibility } \\
\text { requires nominal powers } \\
\text { above } 200 \mathrm{MW}\end{array}$ & $\begin{array}{l}\text { Use of solutions to boost reactivity } \\
\text { could remove the need of enrichment, } \\
\text { giving a } 1 \%-2 \% \text { cost reduction in } \\
\text { energy tariff }\end{array}$ & $\begin{array}{l}\text { Deuterated metals under high neutron flux may } \\
\text { generate neutron absorbing elements. It is } \\
\text { possible pulsed neutron sources with the } \\
\text { required output would be too expensive to build } \\
\text { and operate }\end{array}$ \\
\hline MSR & $\begin{array}{l}\text { Not proven, could be so } \\
\text { risky as PWR. Economic } \\
\text { feasibility requires } \\
\text { nominal powers above } 40 \\
\text { MW }\end{array}$ & $\begin{array}{l}\text { Use of solutions to boost reactivity } \\
\text { could remove the need of enrichment, } \\
\text { giving a } 3 \%-5 \% \text { cost reduction, } \\
\text { radioactive waste burning at low cost }\end{array}$ & $\begin{array}{l}\text { Deuterated metals under high neutron flux may } \\
\text { generate neutron absorbing elements. It is } \\
\text { possible pulsed neutron sources with the } \\
\text { required output would be too expensive to build } \\
\text { and operate }\end{array}$ \\
\hline LMR & $\begin{array}{l}\text { Not proven, navies saw it } \\
\text { as riskier than PWR. } \\
\text { Economic feasibility } \\
\text { requires nominal powers } \\
\text { above } 40 \mathrm{MW}\end{array}$ & $\begin{array}{l}\text { Use of solutions to boost reactivity } \\
\text { could remove the need of enrichment, } \\
\text { giving a } 3 \%-5 \% \text { cost reduction, } \\
\text { radioactive waste burning at low cost }\end{array}$ & $\begin{array}{l}\text { Recent advances did not solve fundamental } \\
\text { problems in LMR design, like corrosion along } \\
\text { leakages and plugging (lead-bismuth) and } \\
\text { explosion risks (sodium), besides the risk of } \\
\text { ruptures in steam generator causing ruptures in } \\
\text { reactor vessel. The risks of solutions for } \\
\text { reactivity boost also apply }\end{array}$ \\
\hline $\begin{array}{l}\text { Magnetic } \\
\text { and Inertial }\end{array}$ & $\begin{array}{l}\text { Not demonstrated yet, so } \\
\text { it is impossible to compare } \\
\text { to fossil fuels }\end{array}$ & $\begin{array}{l}\text { New super magnets along mix of } \\
\text { magnetic and inertial confinements on } \\
\text { deuterated or tritiated metal pellet } \\
\text { could improve COP in orders of size. } \\
\text { Further, the use of plasmoids could } \\
\text { greatly simplify designs and reduce } \\
\text { costs }\end{array}$ & $\begin{array}{l}\text { Insertion of solids increases design complexity } \\
\text { and number of possible reaction products, } \\
\text { possibly generating radioactive waste. Plasmoids } \\
\text { are not well understood yet and may need } \\
\text { revision of plasma physics to be fully explored }\end{array}$ \\
\hline Lattice & $\begin{array}{l}\text { Startups and scientists } \\
\text { claimed successful } \\
\text { prototypes } \\
\text { demonstrations with COP } \\
\text { over unity }\end{array}$ & $\begin{array}{l}\text { One order of size in energy costs } \\
\text { reduction, compared to fossil fuels. } \\
\text { The combination with pulsed neutron } \\
\text { sources could improve reaction } \\
\text { control }\end{array}$ & $\begin{array}{l}\text { The claimed COP may be not practical in real } \\
\text { life situations or reaction control may be } \\
\text { impossible }\end{array}$ \\
\hline
\end{tabular}

hybrid inertial and magnetic confinement, aiming at proton-Boron (p-B11) aneutronic reactions (it is a fission of Boron into lighter Helium). Two particle beams are accelerated in opposite directions and collide in the centre, where there are also plasma injections to form a vortex. The own movement of charged particles helps the confinement, called Field Reversed Configuration (FRC) with neutral beams injections [19], which is a kind of plasmoid. It has already built five prototypes and the concept reactor is compact (about $27 \mathrm{~m}$ length). This company has also a portfolio of adjacent commercial innovations in power management, electric mobility, life sciences and particle accelerator beams. It expects commercialization of p-B11 fusion power plants beginning by the late 2020s. By 2021, this company had received US\$ 880 million and was valuated at US\$ 2.6 billion and it has an extensive collection of scientific papers. One of the most recent papers featured at its website (https://tae.com/research-library/) claims to have obtained fusion rates at orders of magnitude higher than pre- 
dicted by current models [20].

The second enterprise is General fusion, a US company that uses hybrid inertial and magnetic confinement-LINUS concept (Liquid Lithium rotating in a spherical chamber), also called Magnetized Target Fusion (MTF). For magnetic confinement, it has magnetic fields that confine the fuel while it is heated into a plasma, and it is injected in the sphere where liquid Lithium is rotating to make a central cavity. As with the inertial approach, fusion is initiated by rapidly squeezing the target to greatly increase fuel density and temperature. The hydraulic rams operate this compression, and a heat exchanger removes the generated heat from the liquid Lithium and can power a steam turbine. General Fusion is designing a MTF device that compresses a toroidal plasma inside a liquid metal cavity and claims that could build a 40 MWe power plant [21].

The third company is Compact Fusion Reactor (CFR), a subsidiary of Lockheed Martin that claims to have a design of a reactor small enough to fit on a truck that could provide enough power for a small city of up to 100,000 people. It also claims it may develop within 5 years by using compact designs and combines cusp confinement and magnetic mirrors to confine the plasma Employing superconducting magnets. It uses Deuterium and Tritium, which generates neutrons, so it requires shielding. At the website of the project

(https://www.lockheedmartin.com/en-us/products/compact-fusion.html), authors did not find any scientific full paper presenting results.

The fourth is Commonwealth Fusion Systems that uses an advanced TOKAMAK fusion reactor using SPARC design, inspired in ARC (Affordable, Robust, Compact) design of MIT. The design makes use of rare-earth barium-copper-oxide (REBCO) superconducting tape, uses Deuterium and Tritium, which generates neutrons, so it requires shielding, done by a blanket of fluorine lithium beryllium (FLiBe) molten salt, which also generates Tritium for use as fuel. The design has COP near 13.6. Although its TOKAMAK design makes it unlikely to fit in a ship, this project is worth to mention due its compactness. At its website (https://cfs.energy/), this company presents the major milestones for its technology and there is a series of open access papers at a special issue of the Journal of Plasma Physics [22].

The fifth is Zap Energy, that stabilizes plasma using sheared flows rather than magnetic fields. Driving electric current through the flow creates the magnetic field, which confines and compresses the plasma. The higher the current, the greater the pressure and density in the plasma. Uses a sheared flow (plasma flowing at different velocities at different radii). It claims that a sheared flow medium can be confined long enough for the fusion reactions to occur, and it uses Hydrogen-Deuterium mixtures as fuel, requiring shielding against neutrons. At its website (https://www.zapenergyinc.com/research), the company displays a set of scientific papers presenting their results, including sustaining steady neutron emissions for 10 microseconds [23] [24].

The sixth is Lawrenceville Plasma Physics (LPP), that uses an approach called 
"Focus Fusion", which is a hybrid of inertial and magnetic confinement using plasmoids. The plasma is compressed using magnetic self-compression, creating a dense plasma focus for a limited time, at a certain frequency, generating power. It is the combination of the Dense Plasma Focus device with aneutronic hydrogen-boron fuel, using the natural instabilities of plasmas instead of fighting them. This company claims it is possible to make direct conversion of plasma energy to electric power, resulting in a very compact power generator, fitting in a garage and such fusion generators are projected to cut the cost of electricity by over $90 \%$. In 2017, it published a paper reporting a neutron yield per shot of 1.6 e11 neutrons per shot by plasmoids lasting about 40 nano seconds [25]. As the resulting fusion products are ejected in the direction of the axis of the plasmoid [26], it becomes relatively easy to convert the kinetic energy of ions to electric power using a coil.

The seventh is HB11 Energy [15], that uses laser technology to fuse Hydrogen and Boron, where a first laser accelerates hydrogen towards a boron fuel (inertial confinement) and a second laser creates a kilo Tesla magnetic field by hitting a capacitive coil (magnetic confinement enhances reaction yield). The company claims that there is a chain reaction leading to a reaction yield one billion times higher than previously thought and the resulting energetic charged particles generate electricity directly, so steam turbines are not required. This design is based on the work of Heinrich Hora and seems to use lattice confinement (Hydrogen and Boron in solid Silicon lattice), inertial confinement (uses laser) and magnetic confinement (capacitive coil).

The eighth company is Helion Energy, which develops a hybrid of magnetic and inertial confinement using Helium-3 and Deuterium via an almost aneutronic fusion [27]. The Fusion Engine technology is based on the Inductive Plasmoid Accelerator experiments, operating at $1 \mathrm{~Hz}$, injecting plasma, compressing plasma up to fusion conditions, expanding it and directly recovering the energy in form of electricity [14]. It uses plasmoids that are coherent structures of plasma with a Field Reversed Configuration (FRC), which avoids challenges of other architectures where the devices that create, heat, and sustain the plasma must be co-located along with the reactor blanket and power processing systems. The FRC is a plasmoid with a symmetric toroidal geometry in which the confining magnetic field is provided primarily by toroidal plasma currents. The reactor has the form of a simple variable diameter cylinder, making it compact and allowing a high plasma density and the highest magnetic fields intensity. Pulsed magnetic fields accelerate two plasmoids into a fusion compression chamber, resulting in a single target plasmoid at high pressure. The plasmoids start relatively cool in a larger diameter sections and are compressed in a central fusion chamber where the company claims the compression ratio reaches 400 (pressure becomes 400 times larger than in initial volume). In 2021, the firm announced that its Trenta prototype had reached 100 million degrees $\mathrm{C}$ after a 16-month test cycle with more than 10,000 pulses. This firm also claims the direct energy conversion at high efficiency is possible. 
The ninth solution is E-Cat, an invention of Andrea Rossi that uses a mixture of Nickel, Aluminium, Lithium and Hydrogen to catalyse apparently aneutronic nuclear reactions using lattice confinement. A report by Fabio Penon (third-party validator agreed by Industrial Heat and Andrea Rossi), available at E-Cat website [28], claims to have achieved COP ranging from 62 to 142, having an overall of 80 in a 350 day demonstration. A similar technology is Brillouin Energy's Controlled Electron Capture Reaction (CECR) technology which achieved a COP around 2.5 using Hydrogen and Nickel stimulated with proprietary "Q" pulses (https://brillouinenergy.com).

It is important to mention that Andrea Rossi filled a lawsuit against Industrial Heat in 2016 alleging the licensing deal included a US\$89 million fee after a one year successful demonstration [28], which Industrial Heat refused to pay on grounds of lack of proof [29]. Both parties settled in 2017 and Industrial Heat renewed its commitment to keep pursuing this kind of technology, and Industrial Heat valuation reached US\$ 918 valuation in 2019 [30]. In April of 2021, Industrial Heat counted with 9 patents listed in https://uspto.report/company/Industrial-Heat-L-L-C/patents. It is also relevant to note that in beginning of July 2021, https://www.dnb.com/ stated Industrial Heat, LLC had generated \$2.84 million in sales (USD).

Not only private enterprises worked about Nickel-Hydrogen lattice-confinement reactors, but many researchers from academy have reported success in generating heat beyond chemical energy [31] [32] [33] [34].

Other interesting facts are Airbus filled two patents that apparently uses lattice confinement fusion and plasmas [35] [36] and Boing in partnership with NASA drafted a plan to develop the Subsonic Ultra Green Aircraft up to 2035 considering a Ni-H lattice confinement reactor as one possible alternative [37].

After researching some public information about private nuclear fusion enterprises, this work presents some valuations or gathered investments for some of them at Table 5 .

Table 5. List of start-ups using clean nuclear energy concepts.

\begin{tabular}{cccc}
\hline Enterprise & $\begin{array}{c}\text { Valuation } \\
\text { (US\$M) }\end{array}$ & $\begin{array}{c}\text { Investment } \\
\text { (US\$M) }\end{array}$ & Year \\
\hline Industrial Heat & 4000 & & 2019 \\
TAE Technologies (former Tri-Alpha Energy) & 2600 & 880 & 2021 \\
General Fusion & & 200 & 2016 \\
Commonwealth Fusion Systems & 200 & 2020 \\
Tokamak Energy & & 193 & 2020 \\
Helion Energy & 77,8 & 2021 \\
Zap Energy & 14,5 & 2020 \\
HB11 & 4,6 & 2021 \\
Lawrenceville Plasma Physics (LPP) & 2,4 & 2020 \\
\hline
\end{tabular}


The reader can see that Industrial Heat seems to be ahead of competitors, having worked with E-Cat and Brillouin Energy and dozens of other "cold fusion" start-ups.

Energy is not only about price, but also about security, as an interruption in supply may have catastrophic effects in modern societies. Therefore, every large enterprise or government should avoid dependence on a single supplier or in an energy source that has few suppliers, like petrol. Uranium and Thorium are better distributed, and its suppliers are more politically stable. The Nickel is yet more distributed and far more abundant than Uranium, yet Boron concentrates in Turkey and Lithium concentrates in Australia. Anyway, such materials are quite common and abundant in global market, so a shortage or drastic rise in prices perhaps would not affect much the life cycle costs, at least in short term. As nuclear reactors should be quite complex and fuel preparation should be more expensive than raw materials, one can expect that even for lattice confinement reactors capital costs should dominate.

Because energy tariffs are the base of industry competitivity, it is probable that such technologies should be export-restricted due national strategy, the same way as nuclear weapons and Uranium enrichment.

One cannot say if any of the companies will be successful, but if only one is successful, it is sure that the energy market will suffer a major disruption. Current players should go bankrupt because of the appearance of a new player capable of delivering the same product (or even better) with a fraction of cost. This means that the risk of not investing in the field is quite high, given the long times required to arrive to a commercial technology from first principles. A country or a large company without access to fusion technologies should have difficulties to survive if one or more competitors gain access to an energy source one order of magnitude cheaper than current sources. This means fusion technologies are potentially disruptive, as nobody should survive without it if one of them becomes a product, and new businesses could emerge from the abundance of energy.

With a sceptical mind, one recognizes that it is impossible to know for sure if such fantastic claims are true or not without making experiments, but as [38] pointed, science is not a zero-sum game. Research may bring unexpected results, as even if [38] reported failure in some experiment's replication, the same team (funded by Google) found that neutron yields in deuterated Palladium for ions with less than $2 \mathrm{keV}$ are two orders of magnitude larger than current models predict [7]. Such discovery suggests that fusion in deuterated metals may be easier than current models predict.

\section{Conclusion}

The nuclear reactors have the tendency to become more employed in the future given the new technological and experimental advances and small and mobile fusion reactors may arise as a disruptive technology. Anyway, research and de- 
velopment are still needed to achieve practical applications, and although this work cannot state if any of new concepts is truly feasible (or competitive), it is possible that the fifth generation of nuclear reactors will be disruptive. To avoid a scenario of loss of competitivity, this work suggests investing in research following the descending order of potential: aneutronic nuclear reactions using lattice confinement, aneutronic nuclear reactions using inertial along magnetic confinement in plasmoids, hybrid fission-lattice confinement fusion, and fission reactions.

\section{Conflicts of Interest}

The authors declare no conflicts of interest regarding the publication of this paper.

\section{References}

[1] Luciano, O.F. and de Andrade, D.A. (2015) Historic Survey on Nuclear Merchant Ships. Nuclear Engineering and Design, 293, 176-186. https://doi.org/10.1016/j.nucengdes.2015.07.031

[2] Global Construction Review Staff (2021) Russia Plans up to Five Floating Nuclear Power Stations for Northeast Wilderness.

https://www.globalconstructionreview.com/news/russia-plans-five-floating-nuclear -power-stations-/

[3] Strupczewski, A. (2003) Accident Risks in Nuclear-Power Plants. Applied Energy, 75, 79-86. https://doi.org/10.1016/S0306-2619(03)00021-7

[4] Haubenreich, P.N. and Engel, J.R. (1970) Experience with the Molten-Salt Reactor Experiment. Nuclear Applications and Technology, 8, 118-136.

https://doi.org/10.13182/NT8-2-118

[5] Raiola, F. et al. (2006) Enhanced d(d,p)t Fusion Reaction in Metals. The European Physical Journal A-Hadrons and Nuclei, 27, 79-82. https://doi.org/10.1140/epja/i2006-08-011-0

[6] Cvetinovic, A., Lipoglavsek, M., Markelj, S. and Vesic, J. (2015) Molecular Screening in Nuclear Reactions. Physical Review C, 92, Article IDS: 065801. https://doi.org/10.1103/PhysRevC.92.065801

[7] Schenkel, T., Persaud, A., Wang, H., Seidl, P.A., MacFadyen, R., Nelson, C., et al. (2019) Investigation of Light Ion Fusion Reactions with Plasma Discharges. Journal of Applied Physics, 126, Article ID: 203302. https://doi.org/10.1063/1.5109445

[8] Shani, G., et al. (1989) Background Induced D-D Fusion. 5th International Conference on Emerging Nuclear Energy Systems, Karlsruhe, 3-6 July 1989, 304-307.

[9] Stella, B., et al. (1993) Evidence for Stimulated Emission of Neutrons in Deuterated Palladium. 3rd International Conference on Cold Fusion, Nagoya, 21-25 October 1993, 437-440.

[10] Miley, G.H. and Shrestha, P. (2003) Review of Transmutation Reactions in Solids. 10th International Conference on Cold Fusion, Cambridge, 21-29 August 2003, 361-378.

[11] Steinetz, B.M., Benyo, T.L., Chait, A., Hendricks, R.C., Forsley, L.P., Baramsai, B., et al. (2020) Novel Nuclear Reactions Observed in Bremsstrahlung-Irradiated Deuterated Metals. Physical Review C, 101, Article No. 044610. 
https://doi.org/10.1103/PhysRevC.101.044610

[12] Yu, D.A. and Wisniewski, R. (2014) Changes Observed in the Elemental Composition of Palladium and Rhenium Specimens Irradiated in Dense Deuterium by $\gamma$-Quanta with Boundary of Energy $23 \mathrm{MeV}$. Journal of Condensed Matter Nuclear Science, 13, 89-105.

[13] Lipson, A., Chernov, I., Sokhoreva, V., Mironchik, V., Roussetski, A., Tsivadze, A., et al. (2009) Charged Particle Emissions and Surface Morphology of Pd/PdO: Dx and TiDx Targets Under Electron Beam Excitation. Proceedings 15th International Conference on Condensed Matter, Rome, 5-9 October 2009, 187-196.

[14] Slough, J.T. (2018) Method and Apparatus for the Generation, Heating and/or Compression of Plasmoids and/or Recovery of Energy Therefrom. US Patent No. US 20180025792 A1.

[15] Hora, H., Korn, G., Giuffrida, L., Margarone, D., Picciotto, A., Krasa, J., et al. (2015) Fusion Energy Using Avalanche Increased Boron Reactions for Block-Ignition by Ultrahigh Power Picosecond Laser Pulses. Laser and Particle Beams, 33, 607-619. https://doi.org/10.1017/S0263034615000634

[16] Abe, Y., Baba, H. and Yamada, H. [ed.] (2011) Change in Isotopic Ratio of Li by Light Water Electrolysis. Proceedings of the 12th Meeting of Japan Cold Fusion Research Society, Kobe University, Japan, December 17-18, 2011, 35-42.

[17] Biberian, J.-P. (2012) Transmutation of Elements in Low-energy Glow Discharge and the Associated Processes. Journal of Condensed Matter Nuclear Science, 6, 181-198.

[18] Sundarsen, R. and Bockris, J.O’M. (1994) Anomalous Reactions during Arcing Between Carbon Rods. Fusion Technology, 26, 261-265.

https://doi.org/10.13182/FST94-A30330

[19] Tuszewski, M., Smirnov, A., Thompson, M.C., Korepanov, S., Akhmetov, T., Ivanov, A., et al. (2012) Field Reversed Configuration Confinement Enhancement through Edge Biasing and Neutral Beam Injection. Physical Review Letters, 108, Article No. 255008. https://doi.org/10.1103/physrevlett.108.255008

[20] Magee, R.M., Necas, A., Clary, R., Korepanov, S., Nicks, S., Roche, T., Thompson, M.C., et al. (2019) Direct Observation of Ion Acceleration from a Beam-Driven Wave in a Magnetic Fusion Experiment. Nature Physics, 15, 281-286. https://doi.org/10.1038/s41567-018-0389-0

[21] Laberge, M. (2019) Magnetized Target Fusion with a Spherical Tokamak. Journal of Fusion Energy, 38, 199-203. https://doi.org/10.1007/s10894-018-0180-3

[22] The SPARC Team (2020) Status of the SPARC Physics Basis. https://www.cambridge.org/core/journals/journal-of-plasma-physics/collections/sta tus-of-the-sparc-physics-basis

[23] Stepanov, A.D., Shumlak, U., McLean, H.S., Nelson, B.A., Claveau, E.L., Forbes, E.G., et al. (2020) Flow Z-Pinch Plasma Production on the FuZE Experiment. Physics of Plasmas, 27, Article No.112503. https://doi.org/10.1063/5.0020481

[24] Shumlak, U. (2020) Z-Pinch Fusion. Journal of Applied Physics, 127, Article ID: 200901. https://doi.org/10.1063/5.0004228

[25] Lerner, E.J., Hassan, S.M., Karamitsos, I. and Von Roessel, F. (2017) Confined Ion Energy $>200 \mathrm{keV}$ and Increased Fusion Yield in a DPF with Monolithic Tungsten Electrodes and Pre-Ionization. Physics of Plasmas, 24, Article ID: 102708. https://doi.org/10.1063/1.4989859

[26] Bertalot, L., Herold, H., Jäger, U., Mozer, A., Oppenländer, T., Sadowski, M., et al. 
(1980) Mas and Energy Analysis and Space-Resolved Measurements of Ions from Plasma Focus Devices. Physics Letter A, 79, 389-392. https://doi.org/10.1016/0375-9601(80)90272-8

[27] Slough, J.T., Kirtley, D.E. and Pihl, C.J. (2015) Advanced Fuel Cycle and Fusionn Reactores Utilizing the Same. US Patent No. WO2015/163970A2.

[28] Penon, F. (2017) Official ECAT 1MW One Year Report from Expert Responsible for Validation. E-Cat. https://ecat.com/news/page/2

[29] Smith, R.A. (2017) Supplemental Expert Report of Rick A. Smith. Applied Thermal Engineering, Inc., Ohio, 31.

[30] Shubber, K., Smith, R. and Smith, P. (2021) The Long-Shot Science That Attracted Brad Pitt and Neil Woodford. Finantial Times. https://www.ft.com/content/024cfc4a-8df6-11e9-a1c1-51bf8f989972.

[31] Alabin, K.A., Andreev. S., Sobolev, A.G., Zabavin, S.N., Parkhomov, A. and Timerbulatov, T.R. (2018) Isotopic and Elemental Composition of Substance in Nickel-Hydrogen Heat Generators. Journal of Condensed Matter Nuclear Science, 26, 32-44.

[32] Celani, F., Lorenzetti, C., Vassallo, G., Purchi, E., Fiorilla, S., Cupellini, S., et al. (2020) Progress Toward an Understanding of LENR-AHE Effects in Coated Constantan Wires in D2Atmosphere: DC/AC Voltage Stimulation. The Journal of Condensed Matter Nuclear Science Electronic, 33, 1-28.

[33] Iwamura, Y., Itoh, T., Kasagi, J., Murakami, S. and Saito, M. (2020) Excess Energy Generation using a Nano-sized Multilayer Metal Composite and Hydrogen Gas. Journal of Condensed Matter Nuclear Science, 33, 1-13.

[34] Takahashi, A., Yokose, T., Mori, Y., Taniike, A., Furuyama, Y., Ido, H., et al. (2020) Latest Progress in Research on AHE and Circumstantial Nuclear Evidence by Interaction of Nano-Metal and H(D)-Gas. The 22nd International Conference on Condensed Matter Nuclear Science, Assisi, 8-13 September 2019.

[35] Kotzias, B. (2017) Material Arrangement for Fusion Reactor and Method for Producing the Same. US Patent 2017/0025191 A1, G21B 1/19.

[36] Kotzias, B. (2017) Method and Apparatus for Generating and for Fusing Ultra-Dense Hydrogen. US Patent 2017/0022055 A1, C01B 3/00.

[37] Bradley, M.K. and Droney, C.K. (2012) Subsonic Ultra Green Aircraft Research Phase II: N+4 Advanced Concept Development. Langley Research Center, Hampton, NASA/CR-2012-217556.

[38] Berlinguette, C.P., Chiang, Y.-M., Munday, J.N., Schenkel, T., Fork, D.K., Koningstein, R., et al. (2019) Revisiting the Cold Case of Cold Fusion. Nature, 570, 45-51. https://doi.org/10.1038/s41586-019-1256-6 